University of Wollongong

Research Online

Faculty of Engineering and Information

Faculty of Engineering and Information

Sciences - Papers: Part A

Sciences

$1-1-2013$

\title{
Mixed-metal (Li, Al) amidoborane: synthesis and enhanced hydrogen storage properties
}

Guanglin Xia

University of Wollongong, gx168@uowmail.edu.au

Yingbin Tan

Fudan University

Xiaowei Chen

Fudan University

Zaiping Guo

University of Wollongong, zguo@uow.edu.au

Hua-Kun Liu

University of Wollongong, hua@uow.edu.au

See next page for additional authors

Follow this and additional works at: https://ro.uow.edu.au/eispapers

Part of the Engineering Commons, and the Science and Technology Studies Commons

Research Online is the open access institutional repository for the University of Wollongong. For further information contact the UOW Library: research-pubs@uow.edu.au 


\title{
Mixed-metal (Li, Al) amidoborane: synthesis and enhanced hydrogen storage properties
}

\author{
Abstract \\ Mixed-metal ( $\mathrm{Li}, \mathrm{Al}$ ) amidoborane has been synthesized via mechanical ball milling of ammonia borane \\ with lithium hexahydridoaluminate in different molar ratios. The reversible dehydrogenation properties of \\ the thus-synthesized metallic amidoborane and its mixtures with ammonia borane in different ratios were \\ systematically investigated in comparison with neat ammonia borane (AB). On the basis of \\ thermogravimetric analysis and mass spectrometry results, the thus-synthesized mixed-metal \\ amidoborane was shown to release around $10 \mathrm{wt} \%$ hydrogen below 200 degrees $\mathrm{C}$, with an effective \\ suppression of volatile side products. Furthermore, a synergistic effect between metallic amidoborane \\ and ammonia borane has been identified, which leads to the release of $9 \mathrm{wt} \%$ hydrogen with high purity at \\ 120 degrees $C$. Additionally, upon treatment with hydrazine in liquid ammonia, the regenerated products \\ from the decomposed Li3AlH6-nAB $(n=4,5$, and 6$)$ composites can release $3.5 \mathrm{wt} \%$ hydrogen with high \\ purity, corresponding to an approximate $35 \%, 30 \%$, and $26 \%$ regeneration yield for the post-milled \\ Li3AlH6-nAB $(n=4,5$, and 6) composites, respectively.
}

\section{Keywords}

amidoborane, al, properties, li, storage, metal, mixed, hydrogen, enhanced, synthesis

\section{Disciplines}

Engineering | Science and Technology Studies

\section{Publication Details}

Xia, G., Tan, Y., Chen, X., Guo, Z., Liu, H. \& Yu, X. (2013). Mixed-metal (Li, Al) amidoborane: synthesis and enhanced hydrogen storage properties. Journal Of Materials Chemistry A, 1 (5), 1810-1820.

\section{Authors}

Guanglin Xia, Yingbin Tan, Xiaowei Chen, Zaiping Guo, Hua-Kun Liu, and Xuebin Yu 


\section{Journal of \\ Materials Chemistry A}

\section{Mixed-metal (Li, Al) amidoborane: synthesis and enhanced hydrogen storage properties $\dagger$}

Cite this: J. Mater. Chem. A, 2013, 1,

Received 14th October 2012 Accepted 30th November 2012

DOI: $10.1039 / \mathrm{c} 2 \mathrm{ta} 00697 \mathrm{a}$

www.rsc.org/MaterialsA

\author{
Guanglin Xia, ${ }^{\text {ab }}$ Yingbin Tan, ${ }^{a}$ Xiaowei Chen, ${ }^{a}$ Zaiping Guo, ${ }^{\text {bc }}$ Huakun Liu ${ }^{b}$ \\ and Xuebin Yu*a
}

\begin{abstract}
Mixed-metal ( $\mathrm{Li}, \mathrm{Al}$ ) amidoborane has been synthesized via mechanical ball milling of ammonia borane with lithium hexahydridoaluminate in different molar ratios. The reversible dehydrogenation properties of the thus-synthesized metallic amidoborane and its mixtures with ammonia borane in different ratios were systematically investigated in comparison with neat ammonia borane (AB). On the basis of thermogravimetric analysis and mass spectrometry results, the thus-synthesized mixed-metal amidoborane was shown to release around $10 \mathrm{wt} \%$ hydrogen below $200{ }^{\circ} \mathrm{C}$, with an effective suppression of volatile side products. Furthermore, a synergistic effect between metallic amidoborane and ammonia borane has been identified, which leads to the release of $9 \mathrm{wt} \%$ hydrogen with high purity at $120{ }^{\circ} \mathrm{C}$. Additionally, upon treatment with hydrazine in liquid ammonia, the regenerated products from the decomposed $\mathrm{Li}_{3} \mathrm{AlH}_{6}-n \mathrm{AB}(n=4,5$, and 6) composites can release $3.5 \mathrm{wt} \%$ hydrogen with high purity, corresponding to an approximate $35 \%, 30 \%$, and $26 \%$ regeneration yield for the postmilled $\mathrm{Li}_{3} \mathrm{AlH}_{6}-n \mathrm{AB}(n=4,5$, and 6) composites, respectively.
\end{abstract}

\section{Introduction}

In an effort to reduce global warming and the world's dependence on fossil fuels, there has been a strong push towards the so-called hydrogen economy, because hydrogen has the highest energy density of all, and more importantly, water is the only waste product when hydrogen is used in a fuel cell. ${ }^{1}$ Both the generation and storage of hydrogen in sufficient quantities are very challenging problems that need to be overcome for hydrogen technology to be commercialized. Unfortunately, even after several decades of intensive investigation, up to now, no single hydrogen storage material fulfills all the essential application requirements, e.g., volumetric and gravimetric hydrogen capacities, handling pressure and temperature, and regeneration of dehydrogenated products.

Ammonia borane $\left(\mathrm{BH}_{3} \mathrm{NH}_{3}, \mathrm{AB}\right.$ hereafter), with $19.6 \mathrm{wt} \%$ hydrogen capacity and good stability under ambient conditions, as well as recently demonstrated regenerability, ${ }^{2}$ has been extensively investigated as a potential hydrogen storage

${ }^{a}$ Department of Materials Science, Fudan University, Shanghai, China. E-mail yuxuebin@fudan.edu.cn; Tel: +86-21-55664581

${ }^{b}$ Institute for Superconducting and Electronic Materials, University of Wollongong, North Wollongong, Australia. E-mail: zguo@uow.edu.au

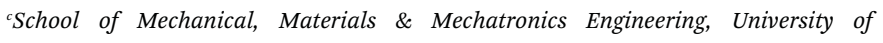
Wollongong, NSW 2522, Australia

$†$ Electronic supplementary information (ESI) available: Powder XRD of the as-prepared $\mathrm{Li}_{3} \mathrm{AlH}_{6}-n \mathrm{AB}(n=4,5$, and 6) composites and its products, TPD results of the products after hydrogenation, and FTIR spectra of the spent fuels. See DOI: $10.1039 / \mathrm{c} 2$ ta00697a candidate. $^{3}$ The relatively high temperature of hydrogen release (over $100{ }^{\circ} \mathrm{C}$ ), however, and the accompanying evolution of volatile by-products (i.e., ammonia, borazine, and diborane), together with its severe foaming and volume expansion during thermal decomposition, significantly hinder the practical application of $\mathrm{AB}$ as a hydrogen storage material. To date, many efficient strategies have been adopted, such as nanoconfinement using nanoscaffolds, ${ }^{4}$ catalysis effects, ${ }^{5}$ ionic liquid assistance, ${ }^{6}$ the hydrolysis reaction, ${ }^{7}$ and chemical modification of $\mathrm{AB}$ via replacing one of its $\mathrm{H}$ atoms with other alkali or alkaline earth elements to form metal amidoboranes, ${ }^{8}$ to surmount the above-mentioned drawbacks. In particular, by dint of modifying the structure of $\mathrm{AB}$, i.e., replacement of a protonic $\mathrm{H}$ atom linked with the $\mathrm{N}$ atom of $\mathrm{AB}$ with a metal cation to form a series of amidoboranes, the kinetics and thermodynamics of hydrogen release can be significantly improved, along with effective suppression of volatile by-products. With respect to this methodology, a number of recent experimental and theoretical investigations have authenticated the correlation between the ionicity and size of metal cations and the nature of the $\mathrm{NH}_{2} \mathrm{BH}_{3}{ }^{-}$bonding in metal amidoboranes, and then determined their individual hydrogen release properties. $^{9}$

In previous reports, studies were mainly focused on the single-metal amidoboranes, e.g., $\mathrm{LiNH}_{2} \mathrm{BH}_{3},{ }^{10} \mathrm{NaNH}_{2} \mathrm{BH}_{3},{ }^{11}$ $\mathrm{KNH}_{2} \mathrm{BH}_{3},{ }^{12} \quad \mathrm{Ca}\left(\mathrm{NH}_{2} \mathrm{BH}_{3}\right)_{2},{ }^{13,14} \quad \mathrm{Sr}\left(\mathrm{NH}_{2} \mathrm{BH}_{3}\right)_{2},{ }^{15}$ and $\mathrm{Y}\left(\mathrm{NH}_{2} \mathrm{BH}_{3}\right)_{3},{ }^{16}$ which have been successfully synthesized through the reaction between ammonia borane and the relevant metal hydrides or halides. Although these single-metal 
amidoboranes exhibited superior hydrogen release properties relative to $\mathrm{AB}$, almost all of them were a source of contamination due to the simultaneous release of ammonia with the hydrogen desorption, ${ }^{\mathbf{1 1}, \mathbf{1 3 - 1 7}}$ which is a very important issue because a very small amount of ammonia (ppm level) poisons the catalysts for proton exchange membrane (PEM) fuel cells. Fortunately, a small number of mixed-metal amidoboranes, e.g., $\mathrm{LiNa}\left(\mathrm{NH}_{2} \mathrm{BH}_{3}\right)_{2},{ }^{18} \mathrm{NaMg}\left(\mathrm{NH}_{2} \mathrm{BH}_{3}\right)_{3},{ }^{19}$ and $\mathrm{Na}_{2} \mathrm{Mg}\left(\mathrm{NH}_{2} \mathrm{BH}_{3}\right)_{4},{ }^{20}$ have been discovered recently through the solid-phase reaction of ammonia borane with the corresponding mixed-metal hydrides, and these demonstrate that the combination of alkali and alkaline earth metals can effectively promote the reactivity of metal hydrides with $\mathrm{AB} .{ }^{8}$ Moreover, $\mathrm{M}_{2} \mathrm{Mg}\left(\mathrm{NH}_{2} \mathrm{BH}_{3}\right)_{4}(\mathrm{M}=\mathrm{Na}$ and $\mathrm{K})$ was also prepared by the mechanical reaction of $\mathrm{Mg}\left(\mathrm{NH}_{2} \mathrm{BH}_{3}\right)_{2} \cdot \mathrm{NH}_{3}$ with $\mathrm{MH} .{ }^{21}$ The thermal stability of the amidoboranes can then be tuned towards favourable dehydrogenation properties. A noteworthy feature is that, due to the incorporation of other structurestabilizing ligands $\left[\mathrm{NaNH}_{2} \mathrm{BH}_{3}\right]$, the $\mathrm{Mg}\left(\mathrm{NH}_{2} \mathrm{BH}_{3}\right)_{2}$ moiety, which is structurally unstable according to a previous report, ${ }^{22}$ is present in some of these mixed-metal amidoboranes, demonstrating the functions of dual-metal ions towards stabilization of unstable complex hydrides, as similarly observed in the synthesis of $\mathrm{MZn}\left(\mathrm{BH}_{4}\right)_{3}(\mathrm{M}=\mathrm{Li}, \mathrm{Na})$, in which the coordination of alkali metals gives rise to the stabilization of $\mathrm{Zn}\left(\mathrm{BH}_{4}\right)_{2}$ under ambient conditions. ${ }^{23}$ Furthermore, significantly improved hydrogen desorption properties were realized for the mixed-metal amidoboranes in comparison with the monometallic amidoboranes, e.g., complete suppression of ammonia was observed for $\mathrm{NaMg}\left(\mathrm{NH}_{2} \mathrm{BH}_{3}\right)_{3},{ }^{19}$ while there is $\sim 15 \mathrm{~mol} \%$ ammonia release for $\mathrm{NaNH}_{2} \mathrm{BH}_{3}$. Therefore, the incorporation of alkali metal ions affords an efficient strategy to stabilize amidoboranes which are thermodynamically unstable under ambient conditions, and meanwhile, offers superior hydrogen desorption properties compared with the single-metal amidoboranes.

Based on the above discussion, synthesis based on the milling-induced solid-phase reaction of $\mathrm{Li}_{3} \mathrm{AlH}_{6}$ with ammonia borane was conducted in this study. This reaction leads to the formation of a mixed alkali metal (Li) and trivalent metal (Al) based metallic amidoborane, which has been proved to possess facile hydrogen release properties without emission of any byproducts. More importantly, the as-prepared mixed-metal ( $\mathrm{Li}$, $\mathrm{Al}$ ) amidoborane was shown to be regenerated through treatment with hydrazine in liquid ammonia to some extent, exhibiting an inspiring breakthrough for amidoboranes as future energy carriers.

\section{Experimental}

\subsection{Materials and synthesis}

The starting materials, $\mathrm{LiAlH}_{4}(97 \%), \mathrm{LiH}(95 \%)$, and $\mathrm{BH}_{3} \mathrm{NH}_{3}$ (97\%), were purchased form Sigma-Aldrich and used in asreceived form without further purification. Samples of $\mathrm{Li}_{3} \mathrm{AlH}_{6}$ were synthesized by mixing stoichiometric ratios $(1: 2)$ of $\mathrm{LiAlH}_{4}$ and LiH powders via planetary ball milling (QM-1SP2, $400 \mathrm{rpm}$, ball to powder ratio of $30: 1$ ) for $24 \mathrm{~h}^{.24}$ The mixed product was then loaded into a stainless steel tube under 80 atm $\mathrm{H}_{2}$ atmosphere, and, in order to improve the purity of the synthesized $\mathrm{Li}_{3} \mathrm{AlH}_{6}$, the ball-milled products were heated with a ramp of $1 \mathrm{~K} \mathrm{~min}^{-1}$ to $150{ }^{\circ} \mathrm{C}$ and annealed at $150{ }^{\circ} \mathrm{C}$ overnight. Combinations of $\mathrm{Li}_{3} \mathrm{AlH}_{6}$ and $\mathrm{BH}_{3} \mathrm{NH}_{3}$ with various molar ratios were ball milled in the planetary QM-1SP2 mill at $350 \mathrm{rpm}$ under argon for $3 \mathrm{~h}$, using stainless steel spheres with a ball-topowder weight ratio of $40: 1$. To reduce the heat effect during the ball-milling process, the mill was set to revolve for $30 \mathrm{~min}$ in one direction, pause for $30 \mathrm{~min}$, and then revolve in the reverse direction. In the control experiment, mixtures of $\mathrm{LiAlH}_{4}$ and $\mathrm{AB}$ were ball milled under identical conditions with different molar ratios. All sample handling was performed in a Ar-filled glove box due to the extreme air-sensitivity of the hydrides.

\subsection{Regeneration}

The regeneration process was similar to the procedure in a previous report: ${ }^{2 a}$ in a typical case, the dehydrogenated composites ( $\sim 100 \mathrm{mg}$ ) after heating to $400{ }^{\circ} \mathrm{C}$ were suspended in liquid ammonia $(\sim 30 \mathrm{~mL})$ at $0{ }^{\circ} \mathrm{C}$ in a stainless steel reaction vessel with an internal volume of $75 \mathrm{~mL}$. Hydrazine was acquired from hydrazine sulfate located on dense stainless nets, which were inserted at the top of the stainless steel vessel and used to prevent hydrazine sulfate contamination of the regenerated products. Subsequently, the reaction vessel was sealed and heated to a constant temperature of $40{ }^{\circ} \mathrm{C}$ for 3 days, and after that, the vessel was vacuum-dried to remove the residual ammonia for $\sim 12 \mathrm{~h}$, with the remnant of the regenerated products on the bottom.

\subsection{Characterization}

Simultaneous thermogravimetric analysis (TGA, Netzsch STA 449C) and mass spectrometry (MS, Hidden HPR 20) were simultaneously applied to survey the hydrogen release properties, using a heating rate of $2{ }^{\circ} \mathrm{C} \mathrm{min}{ }^{-1}$ under dynamic nitrogen

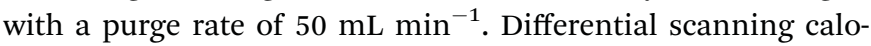
rimetry (DSC) was performed on a TA Q2000, USA, using a heating rate of $2{ }^{\circ} \mathrm{C} \mathrm{min}^{-1}$, with highly pure $\mathrm{N}_{2}$ as the purge gas. Temperature-programmed desorption (TPD) was also conducted to determine the decomposition behavior of the samples under heating on a semi-automatic Sievert's apparatus connected to the reactor containing the sample $(\sim 0.1 \mathrm{~g})$ under 1 atm nitrogen, using a heating rate of $2{ }^{\circ} \mathrm{C} \mathrm{min}^{-1}$. Powder X-ray diffraction (XRD, Rigaku D/max 2400) measurements were performed to confirm the phase structure using $\mathrm{Cu} \mathrm{K} \alpha$ radiation. Samples were mounted on a glass board in an Ar-filled glove box and then sealed with an airtight hood composed of an amorphous membrane in order to avoid oxidation during XRD measurement. High-resolution X-ray diffraction data were collected by a Mythen-II detector with a wavelength of $0.825 \AA$ A t the Powder Diffraction Beamline, Australian Synchrotron. The sample was loaded into a pre-dried $0.7 \mathrm{~mm}$ boron-silica glass capillary, and then, the capillary was sealed with vacuum grease in a glove box filled with argon. In order to identify the phase transformations during decomposition, time-resolved in situ measurements were conducted using a Cyberstar hot-air blower 
to heat the capillary from room temperature to $200{ }^{\circ} \mathrm{C}$, with a constant heating rate of $6{ }^{\circ} \mathrm{C} \mathrm{min}^{-1}$. Data were collected with an exposure time of $150 \mathrm{~s}$ at every $10{ }^{\circ} \mathrm{C}$ step. Fourier transform infrared spectroscopy (FTIR, Magna-IR 550 II, Nicolet) was conducted to confirm the chemical bonds in the samples. Samples were pressed with $\mathrm{KBr}$ and then loaded into a sealed chamber for measurement. Solid-state ${ }^{11} \mathrm{~B}$ nuclear magnetic resonance (NMR, DSX 300) results were collected using a Doty cross-polarization magic angle spinning (CP-MAS) probe with no probe background. All of the solid samples were spun at $12 \mathrm{kHz}$, using $4 \mathrm{~mm} \mathrm{ZrO}_{2}$ rotors filled in a purified argon atmosphere glove box. $0.55 \mu \mathrm{s}$ single-pulse excitation was employed, with repetition time of $1.5 \mathrm{~s}$.

\section{Results and discussion}

\subsection{Phase/structure analysis}

The mixed-metal amidoborane composites were prepared by directly ball milling different molar ratios $(1: 4,1: 5$, and $1: 6)$ of lithium hexahydridoaluminate $\left(\mathrm{Li}_{3} \mathrm{AlH}_{6}\right)$ with ammonia borane $\left(\mathrm{NH}_{3} \mathrm{BH}_{3}, \mathrm{AB}\right)$, and further characterized by powder $\mathrm{X}$ ray diffraction (XRD), as shown in Fig. 1 and $\mathrm{S} 1$ in the ESI. $\dagger$ According to the high-resolution XRD results (Fig. 1) for the ball-milled $\mathrm{Li}_{3} \mathrm{AlH}_{6}$ and $\mathrm{AB}$ with a molar ratio of $1: 4$, the peaks pertinent to the pristine $\mathrm{Li}_{3} \mathrm{AlH}_{6}$ and $\mathrm{AB}$ precursors have disappeared, and meanwhile, a new set of strong peaks have appeared, suggesting the formation of new crystalline phases from the milling-induced solid-phase interaction. In addition, with different molar ratios of the raw materials, except for the peaks belonging to residual $\mathrm{AB}$ due to increased $\mathrm{AB}$ content in the composites, identical peak positions were observed, indicative of the formation of the same phase, owing to the reaction between $\mathrm{Li}_{3} \mathrm{AlH}_{6}$ and $\mathrm{AB}$. Further evidence for the occurrence of the reaction was given by the phenomenon that during the ballmilling process, a gradual pressure increase was detected due to the release of hydrogen, which was subsequently certified as the

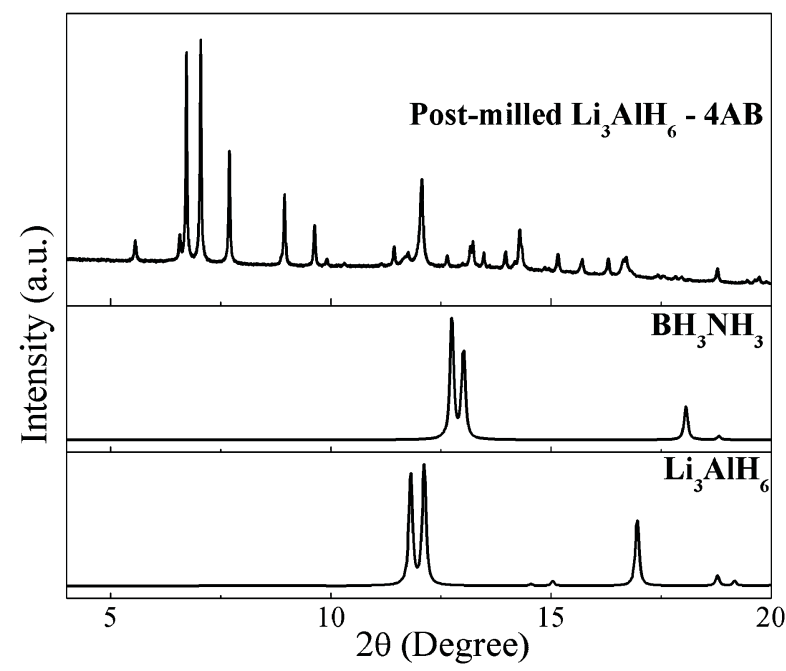

Fig. 1 High-resolution $X$-ray diffraction pattern of the post-milled $\mathrm{Li}_{3} \mathrm{AlH}_{6}-4 \mathrm{AB}$ composite, with the patterns of pristine $A B$ and $\mathrm{Li}_{3} \mathrm{AlH}_{6}$ included for comparison. sole gaseous species via mass spectrometry (MS), resulting in approximately 4 equiv. $\mathrm{H}_{2}$ per $\mathrm{Li}_{3} \mathrm{AlH}_{6}$ for different molar ratios of $\mathrm{Li}_{3} \mathrm{AlH}_{6}$ with $\mathrm{AB}$, based on the calculation from the standard gas equation from the known vessel volume for ball milling and the pressure change. These results also revealed that the reaction of $\mathrm{Li}_{3} \mathrm{AlH}_{6}$ with $\mathrm{AB}$ in various molar ratios proceeded by a parallel pathway, resulting in the formation of the mixed-metal amidoborane with the presence of residual raw materials. As a result, rather than the complete consumption of hydrogen atoms in $\mathrm{Li}_{3} \mathrm{AlH}_{6}$, only four $\mathrm{H}$ atoms of $\mathrm{Li}_{3} \mathrm{AlH}_{6}$ reacted with the $\mathrm{H}^{\delta+}$ in $\mathrm{NH}_{3} \mathrm{BH}_{3}$, leading to the formation of the mixedmetal amidoborane with a chemical composition of $\mathrm{Li}_{3} \mathrm{AlH}_{2}\left(\mathrm{NH}_{2} \mathrm{BH}_{3}\right)_{4}$. Unfortunately, attempts to index the crystal structure of the as-prepared product from the HRXRD pattern failed in the present work, probably due to the poor crystallinity and the possible formation of the mixed-phase of metallic amidoboranes induced during the mechanical preparation process. Apparently, the affinity of $\mathrm{H}^{\delta-}$ in $\mathrm{Li}_{3} \mathrm{AlH}_{6}$ and $\mathrm{H}^{\delta+}$ in $\mathrm{NH}_{3}$ of $\mathrm{AB}$ is one of the main driving forces for this solid-phase reaction, accompanied by the release of $\mathrm{H}_{2}$, comparable to the mechanism for the formation of other metallic amidoboranes. ${ }^{10-15,18-20}$

In order to acquire better information on the reaction products derived from $\mathrm{Li}_{3} \mathrm{AlH}_{6}$ and $\mathrm{AB}$, chemical bonds of the samples were detected by solid-state ${ }^{11} \mathrm{~B}$ NMR and FTIR spectra. The ${ }^{11} \mathrm{~B}$ NMR results (Fig. 2) exhibit the dominant $\mathrm{BH}_{3}$ resonance centered at $-26.3 \mathrm{ppm}$ from neat $\mathrm{AB}$ in accordance with previous reports, ${ }^{25}$ while the resonance for the $\mathrm{BH}_{3}$ group shifts downfield to around $-20.1 \mathrm{ppm}$ in the post-milled $\mathrm{Li}_{3} \mathrm{AlH}_{6}-4 \mathrm{AB}$ sample, similar to the trends for the previously reported metallic amidoboranes, due to the incorporation of metal cations with higher electron densities, leading to the formation of stronger donor complexes with borane..$^{\mathbf{1 0 a , 1 9 , 2 6}}$ Moreover, the fact that only one principal peak is observed for the thussynthesized product from the mechanically milled $\mathrm{Li}_{3} \mathrm{AlH}_{6}-4 \mathrm{AB}$ suggests the same chemical environment for all the boron sites. Additionally, with increasing amounts of $\mathrm{AB}$ in the raw

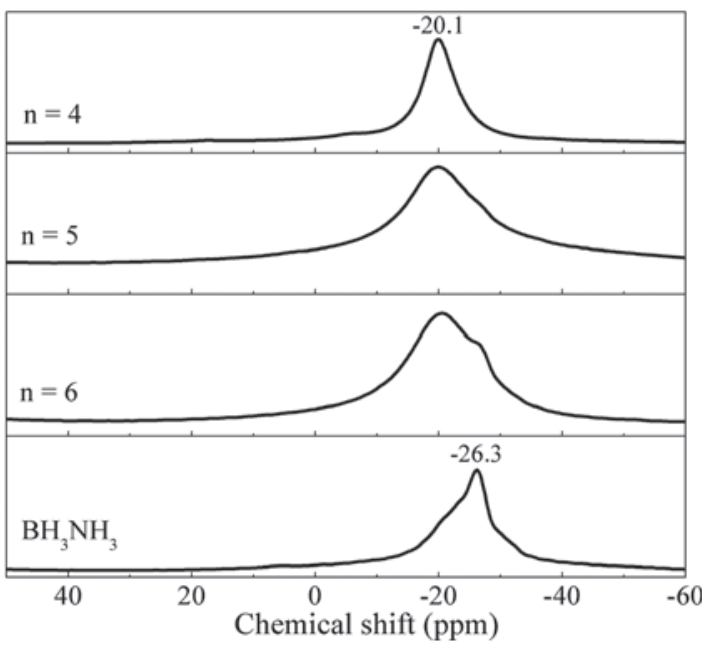

Fig. 2 Solid-state ${ }^{11} \mathrm{~B}$ NMR spectra of the as-prepared $\mathrm{Li}_{3} \mathrm{AlH}_{6}-n \mathrm{AB}(n=4,5$, and 6) composites, including pure $A B$ for comparison. 
materials, the line width for the resonance of the $\mathrm{BH}_{3}$ moiety is broadened, instead of splitting into two peaks attributable to the thus-synthesized mixed-metal amidoborane and the residual $\mathrm{AB}$, respectively, due to the relatively low resolution of solid-state NMR spectra. Furthermore, the resonance for the mobile phase of $\mathrm{AB},{ }^{25,27}$ which has a high reactivity compared to its parent $\mathrm{AB}$, was also observed as a shoulder on the primary peak belonging to the as-prepared mixed-metal amidoborane for the sample with a molar ratio of $\mathrm{AB}: \mathrm{Li}_{3} \mathrm{AlH}_{6}=6: 1$, indirectly demonstrating the partial reaction between $\mathrm{Li}_{3} \mathrm{AlH}_{6}$ and $\mathrm{AB}$ rather than the complete consumption of $\mathrm{H}^{\delta-}$ in $\mathrm{Li}_{3} \mathrm{AlH}_{6}$ during the reaction process. ${ }^{20}$ Analogous to the NMR results, after replacing $\mathrm{H}^{\delta+}$ in $\mathrm{NH}_{3}$ of $\mathrm{AB}$ by metal cations, significant bonding structure changes were observed in the FTIR spectra of the resultant products in comparison with their raw substrates, i.e., $\mathrm{Li}_{3} \mathrm{AlH}_{6}$ and $\mathrm{AB}$. The FTIR results (Fig. 3) show that identical peaks were observed for all the thus-prepared samples, even though there were different molar ratios of $\mathrm{Li}_{3} \mathrm{AlH}_{6}$ to $\mathrm{AB}$. The peak positions of the N-H and $\mathrm{B}-\mathrm{H}$ bonds at around $3150-$ $3350 \mathrm{~cm}^{-1}$ and $2200-2400 \mathrm{~cm}^{-1}$, respectively, in stretching modes are comparable with those of pure ammonia borane, while the peaks of the bending modes for $\mathrm{N}-\mathrm{H}$ bonds and $\mathrm{B}-\mathrm{H}$ bonds are split into two peaks and three peaks, respectively, indicating the complexity of the bonding structure, as well as the reduced structural symmetry of the as-prepared compounds compared with $\mathrm{AB}$, which is also observed for other monometallic amidoboranes ${ }^{16,17}$ and $\mathrm{NaMg}\left(\mathrm{NH}_{2} \mathrm{BH}_{3}\right)_{3} \cdot{ }^{19}$ In addition, the peak at around $864 \mathrm{~cm}^{-1}$ assigned to the bending mode of the LiAl-H bond was present, ${ }^{28}$ providing further evidence for the validity of the incomplete depletion of $\mathrm{H}$ atoms when

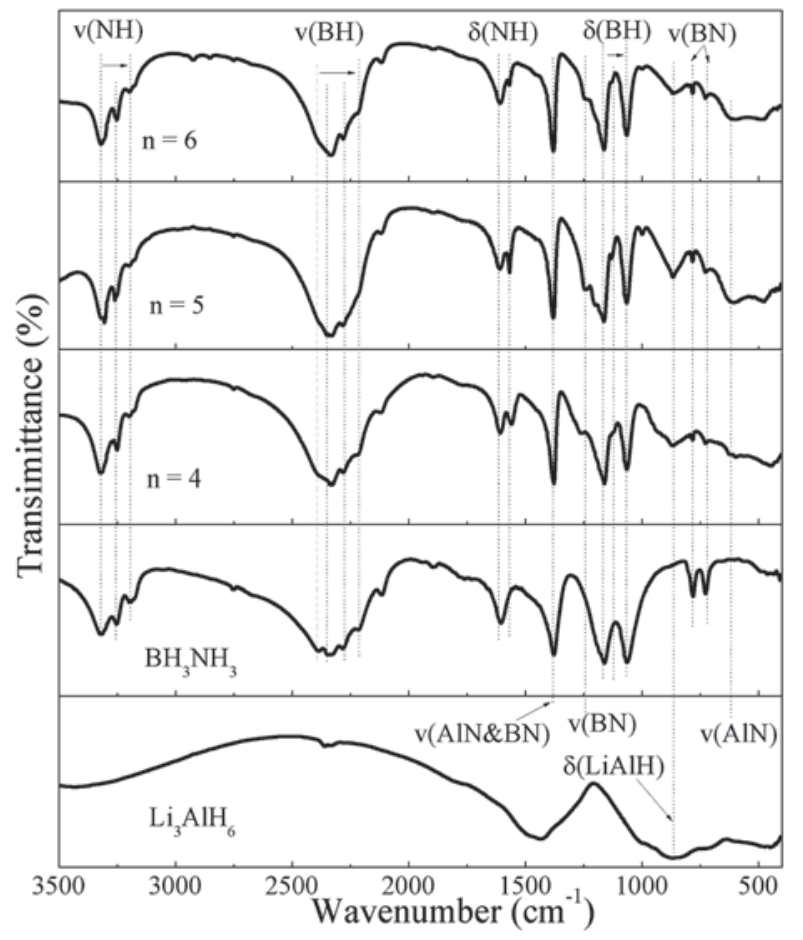

Fig. 3 FTIR spectra of the as-prepared $\mathrm{Li}_{3} \mathrm{AlH}{ }_{6}-n \mathrm{AB}(n=4,5$, and 6$)$ composites, including spectra of pristine $A B$ and as-prepared $\mathrm{Li}_{3} \mathrm{AlH}_{6}$ for comparison.
$\mathrm{Li}_{3} \mathrm{AlH}_{6}$ reacts with $\mathrm{AB}$ during the ball-milling process. Interestingly, a weak band at around $618 \mathrm{~cm}^{-1}$, attributed to the stretching mode of the Al-N bond, is present in all the postmilled samples, which directly confirms the interaction between $\mathrm{Li}_{3} \mathrm{AlH}_{6}$ and $\mathrm{AB}$ during ball milling, leading to substitution for hydridic hydrogen by the $\mathrm{NH}_{2} \mathrm{BH}_{3}{ }^{-}$group to form the mixed-metal amidoborane. Moreover, the strong band at $1380 \mathrm{~cm}^{-1}$ corresponds to the combination of B-N stretching and $\mathrm{Al}-\mathrm{N}$ stretching resonances. The increase in the relative intensity of this peak after ball milling compared with other peaks may be attributed to the formation of Al-N bonds due to the reaction of $\mathrm{Li}_{3} \mathrm{AlH}_{6}$ with $\mathrm{AB}$.

With reference to the reaction of $\mathrm{LiAlH}_{4}$ with ammonium halides, ${ }^{29}$ e.g., $\mathrm{NH}_{4} \mathrm{Cl}$, accompanied by violent hydrogen release resulting from the combination of 3 equiv. $\mathrm{Al}-\mathrm{H}$ bonds and 3 equiv. $\mathrm{N}-\mathrm{H}$ bonds, the reaction of $\mathrm{LiAlH}_{4}$ with $\mathrm{AB}$ has been attempted in an effort to synthesize lithium aluminum amidoboranes. However, attempts to conduct this reaction have failed due to the significant release of boric byproducts (i.e., diborane and borazine) together with hydrogen desorption, even during a hand milling process, resulting in the formation of amorphous products and $\mathrm{Al}$ (Fig. S2 $†$ ). Therefore, the incorporation of $\mathrm{LiH}$ into $\mathrm{LiAlH}_{4}$, i.e., the formation of $\mathrm{Li}_{3} \mathrm{AlH}_{6}$, plays an important role in stabilizing the reaction between $\mathrm{Al}-\mathrm{H}$ bonds and $\mathrm{N}-\mathrm{H}$ bonds, indicating the crucial functionality of the alkali metal in tuning the reactivity of metal hydrides with $\mathrm{AB}$.

\subsection{Hydrogen desorption properties}

For comparison with $\mathrm{AB}$, the thermal decomposition performances of the post-milled $\mathrm{Li}_{3} \mathrm{AlH}_{6}-n \mathrm{AB}(n=4,5$, and 6) were investigated by employing mass spectrometry (MS), and the results are shown in Fig. 4 and S3. $†$ The effective suppression of boric impurities during the decomposition of ammonia borane, i.e., borazine and diborane, was successfully achieved in the asprepared $\mathrm{Li}_{3} \mathrm{AlH}_{6}-n \mathrm{AB}(n=4,5$, and 6) composites. Moreover, the evolution of ammonia was reduced to levels below the detection threshold of mass spectrometry in the cases of the $\mathrm{Li}_{3} \mathrm{AlH}_{6}-n \mathrm{AB}$ ( $n=4$ and 5 ) composites, and only a slight amount of ammonia was released for the $\mathrm{Li}_{3} \mathrm{AlH}_{6}-6 \mathrm{AB}$ composite, indicating significantly improved hydrogen release purity for the $\mathrm{Li}_{3} \mathrm{AlH}_{6}-n \mathrm{AB}$ composites in comparison with the neat $\mathrm{AB}$. Additionally, compared with the dehydrogenation of neat $\mathrm{AB}$ with only two dominant peaks at around $118{ }^{\circ} \mathrm{C}$ and $160{ }^{\circ} \mathrm{C},{ }^{30}$ multiple hydrogen release peaks appear during the decomposition of the $\mathrm{Li}_{3} \mathrm{AlH}_{6}-n \mathrm{AB}(n=4,5$, and 6) composites, which are similar to the hydrogen release process of other reported metallic amidoboranes, ${ }^{\mathbf{1 0}, \mathbf{1 5 - 2 0}}$ suggesting distinct mechanisms for the thermolysis process causing hydrogen desorption. Specifically, $\mathrm{Li}_{3} \mathrm{AlH}_{6}-4 \mathrm{AB}$ starts to release hydrogen at around $82{ }^{\circ} \mathrm{C}$, with a two-step dehydrogenation process that peaks at $99.7{ }^{\circ} \mathrm{C}$ and $148.9{ }^{\circ} \mathrm{C}$, respectively, much lower than that for pure $\mathrm{AB}$. In the case of the $\mathrm{Li}_{3} \mathrm{AlH}_{6}-5 \mathrm{AB}$ composite, the onset hydrogen release temperature further decreases to around 56 ${ }^{\circ} \mathrm{C}$, approximately $26{ }^{\circ} \mathrm{C}$ and $49{ }^{\circ} \mathrm{C}$ lower than for the $\mathrm{Li}_{3} \mathrm{AlH}_{6}-$ $4 \mathrm{AB}$ and the neat $\mathrm{AB}\left(\sim 105{ }^{\circ} \mathrm{C}\right.$ for $\left.\mathrm{BH}_{3} \mathrm{NH}_{3}\right)$, respectively. Meanwhile, the first hydrogen evolution peak is reduced to 


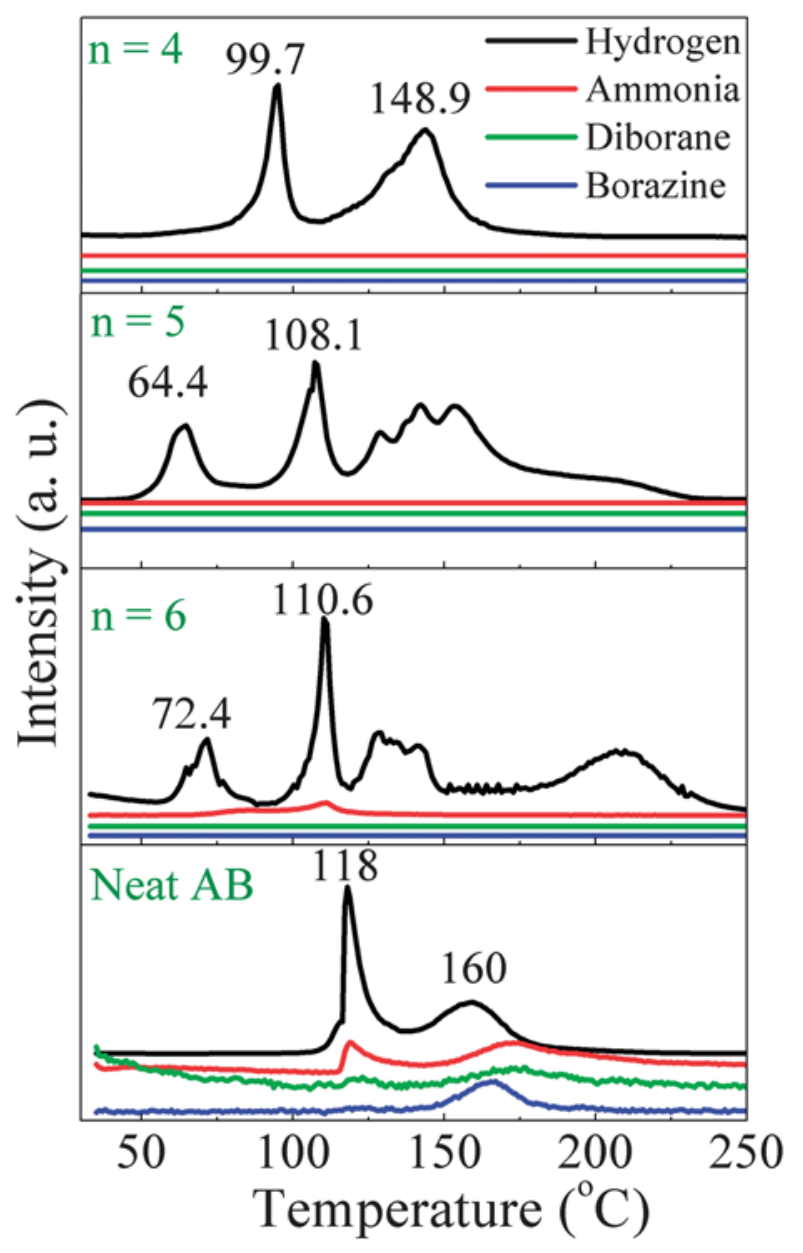

Fig. 4 MS spectra of the as-prepared $\mathrm{Li}_{3} \mathrm{AlH}_{6}-n \mathrm{AB}(n=4,5$, and 6) composites with a heating rate of $2{ }^{\circ} \mathrm{C} \mathrm{min}^{-1}$ under 1 atm dynamic $\mathrm{N}_{2}$ atmosphere, including neat $A B$ for comparison.

$64.4{ }^{\circ} \mathrm{C}$, a remarkable decrease, even in comparison with lithium amidoborane $\left(\sim 91^{\circ} \mathrm{C}\right.$ for $\left.\mathrm{LiNH}_{2} \mathrm{BH}_{3}\right)$, while the second hydrogen evolution peak is centered at $108.1{ }^{\circ} \mathrm{C}$. Thereafter, multiple hydrogen release peaks are present in the temperature range from $120{ }^{\circ} \mathrm{C}$ to $180{ }^{\circ} \mathrm{C}$, illustrating its complicated decomposition mechanism. Comparable results were also observed for the post-milled $\mathrm{Li}_{3} \mathrm{AlH}_{6}-\mathrm{AB}$ composite with a molar ratio of $1: 6$, with the first hydrogen release peak at $72.4{ }^{\circ} \mathrm{C}$ and a following broad peak at temperatures from $180{ }^{\circ} \mathrm{C}$ to $240{ }^{\circ} \mathrm{C}$. Some evolution of ammonia was identified, however, during the dehydrocoupling process ranging from $67{ }^{\circ} \mathrm{C}$ to $132{ }^{\circ} \mathrm{C}$. Moreover, it is noteworthy that the as-synthesized $\mathrm{Li}_{3} \mathrm{AlH}_{6}-n \mathrm{AB}$ composites are free from volume expansion, which is one of the major problems suffered by $\mathrm{AB}$ during hydrogen desorption. As per the above-mentioned results, $\mathrm{Li}_{3} \mathrm{AlH}_{6}-n \mathrm{AB}$ composites exhibit substantially enhanced hydrogen release properties compared with pure ammonia borane, including the effective suppression of volatile boric impurities and much lower hydrogen release temperatures.

Thermogravimetric analysis (TGA) combined with volumetric temperature programmed desorption (TPD) measurements were subsequently performed to quantitatively identify the capacity and purity of hydrogen release from the $\mathrm{Li}_{3} \mathrm{AlH}_{6}-$ $n \mathrm{AB}\left(n=4,5\right.$, and 6) composites. As shown in Fig. $5, \mathrm{Li}_{3} \mathrm{AlH}_{6}-$ $4 \mathrm{AB}$ presents a two-step decomposition, with $3.85 \mathrm{wt} \%$ weight loss for the first step in the region of $80-110{ }^{\circ} \mathrm{C}$ and $6.25 \mathrm{wt} \%$ for the second step from $110^{\circ} \mathrm{C}$ to $175^{\circ} \mathrm{C}$, in good correspondence with the volumetric results $(\sim 3.25$ equiv. and $\sim 5.3$ equiv. for the first and second dehydrogenation steps, respectively), demonstrating the release of hydrogen with high purity, as indicated in the MS spectra. This result indicates the superior effects of the as-prepared mixed-metal ( $\mathrm{Li}, \mathrm{Al})$ amidoborane on suppressing ammonia release compared with other dual-metal amidoboranes. ${ }^{18-20}$ With regard to the $\mathrm{Li}_{3} \mathrm{AlH}_{6}-5 \mathrm{AB}$ composite, the total weight loss is around $12 \mathrm{wt} \%$ over the whole decomposition, corresponding to 12 equiv. $\mathrm{H}_{2}$, which is also consistent with the volumetric results ( $\sim 12.32$ equiv.), again confirming the release of high-purity hydrogen in this composite. Thus far, multiple volatile by-products due to the decomposition of residual ammonia borane can be effectively suppressed by the presence of the thus-synthesized mixed-metal amidoborane in a theoretical molar ratio of $1: 1$. By contrast, the TGA results for the $\mathrm{Li}_{3} \mathrm{AlH}_{6}-6 \mathrm{AB}$ sample give a weight loss of $13.6 \mathrm{wt} \%$, corresponding to approximately 15.7 equiv. $\mathrm{H}_{2}$, while only 14.27 equiv. gas is evolved according to the volumetric results,
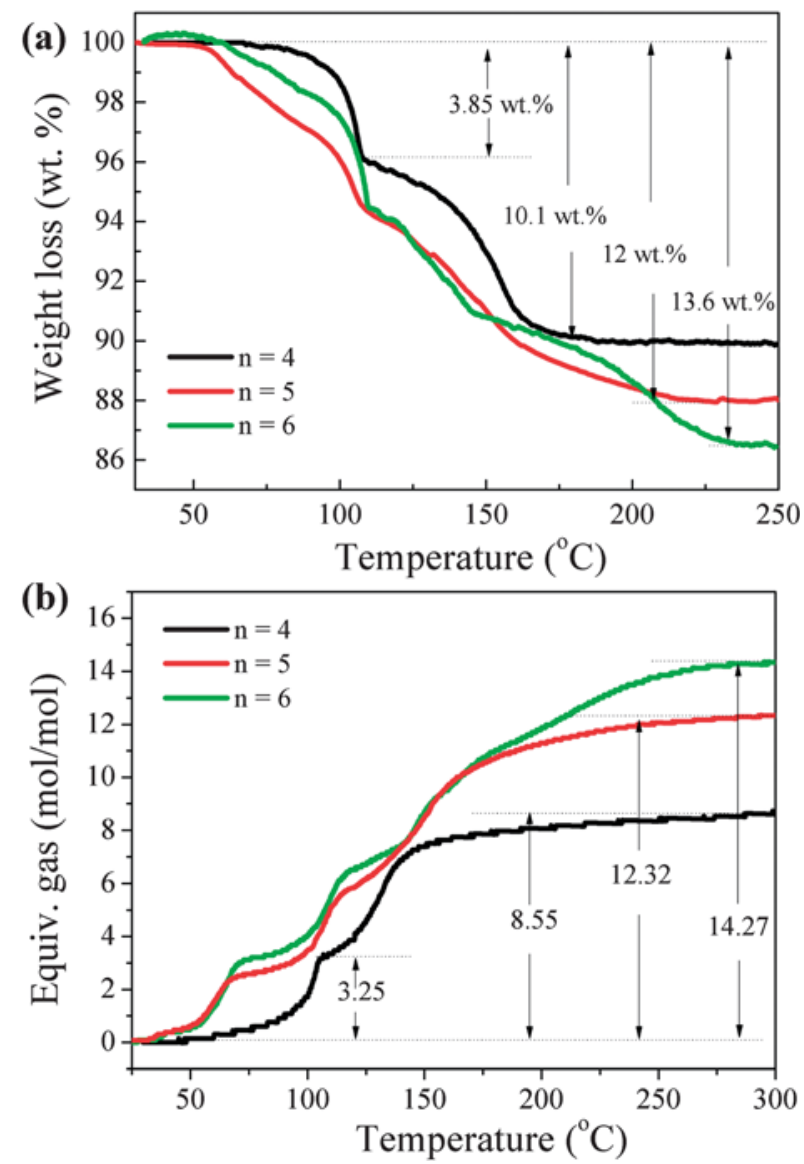

Fig. 5 (a) TGA and (b) volumetric results for the decomposition of the postmilled $\mathrm{Li}_{3} \mathrm{AlH}_{6}-n \mathrm{AB}\left(n=4,5\right.$, and 6) composites at a heating rate of $2{ }^{\circ} \mathrm{C} \mathrm{min}^{-1}$ under 1 atm $\mathrm{N}_{2}$ atmosphere. 
suggesting the presence of by-products during the dehydrogenation process, i.e., ammonia, as detected by the MS spectra. Given that ammonia is the only by-product in conjunction with the dehydrogenation during its decomposition, on the basis of the TGA and volumetric results, the $\mathrm{H}_{2}$ content evolved during decomposition of $\mathrm{Li}_{3} \mathrm{AlH}_{6}-6 \mathrm{AB}$ composite was calculated to be $98.7 \mathrm{~mol} \%$ (89.7 $\mathrm{wt} \%)$, reflecting the fact that the thus-synthesized mixed-metal amidoborane not only exhibits superior hydrogen release properties, but also plays an important role in suppressing the release of volatile side products during the decomposition of residual ammonia borane, e.g., ammonia, borazine, and diborane.

Insights into the dehydrogenation kinetics of $\mathrm{Li}_{3} \mathrm{AlH}_{6}-n \mathrm{AB}$ composites were gained by applying the volumetric desorption measurements at different temperatures. As displayed in Fig. 6, with increasing operating temperature, faster kinetics is yielded for the $\mathrm{Li}_{3} \mathrm{AlH}_{6}-n \mathrm{AB}$ composites. $\mathrm{Li}_{3} \mathrm{AlH}_{6}-4 \mathrm{AB}$ released $4 \mathrm{wt} \%$ hydrogen at $90{ }^{\circ} \mathrm{C}$ and $4.2 \mathrm{wt} \%$ hydrogen at $100{ }^{\circ} \mathrm{C}$ within $100 \mathrm{~min}$. Upon further elevating the temperature to $120^{\circ} \mathrm{C}$ and $130{ }^{\circ} \mathrm{C}$, hydrogen capacities of $\sim 7 \mathrm{wt} \%$ and $9.3 \mathrm{wt} \%$ can be reached, respectively, in $200 \mathrm{~min}$, after a drastic hydrogen evolution within several minutes. In the case of $\mathrm{Li}_{3} \mathrm{AlH}_{6}-5 \mathrm{AB}$, enhanced hydrogen release kinetics was present above $90{ }^{\circ} \mathrm{C}$ compared with the $\mathrm{Li}_{3} \mathrm{AlH}_{6}-4 \mathrm{AB}$. In particular, at $120^{\circ} \mathrm{C}$, around $8 \mathrm{wt} \%$ hydrogen was released within only $45 \mathrm{~min}$. With respect to the $\mathrm{Li}_{3} \mathrm{AlH}_{6}-6 \mathrm{AB}$, further improved dynamic performance was exhibited, especially at relatively low operating temperatures in comparison with the $\mathrm{Li}_{3} \mathrm{AlH}_{6}-5 \mathrm{AB}$. For instance, $5 \mathrm{wt} \%$, $6 \mathrm{wt} \%$, and $7 \mathrm{wt} \%$ hydrogen evolution could be accomplished at temperatures of $80{ }^{\circ} \mathrm{C}, 90{ }^{\circ} \mathrm{C}$, and $110{ }^{\circ} \mathrm{C}$ within $200 \mathrm{~min}$, respectively, which are around $1 \mathrm{wt} \%$ higher than for $\mathrm{Li}_{3} \mathrm{AlH}_{6}-$ $5 \mathrm{AB}$ under the same conditions. For a quantitative evaluation of the kinetic properties related to hydrogen release, the apparent activation energies were calculated from various isothermal dehydrogenation results via linear Arrhenius plots of $\ln k$, where $k$ is the rate constant, as a function of $1 / T$. Fig. $6(\mathrm{~d})$ displays the details for calculation of apparent activation energies. It gives activation energies of approximately $32.6 \mathrm{~kJ} \mathrm{~mol}^{-1}, 27.7 \mathrm{~kJ}$
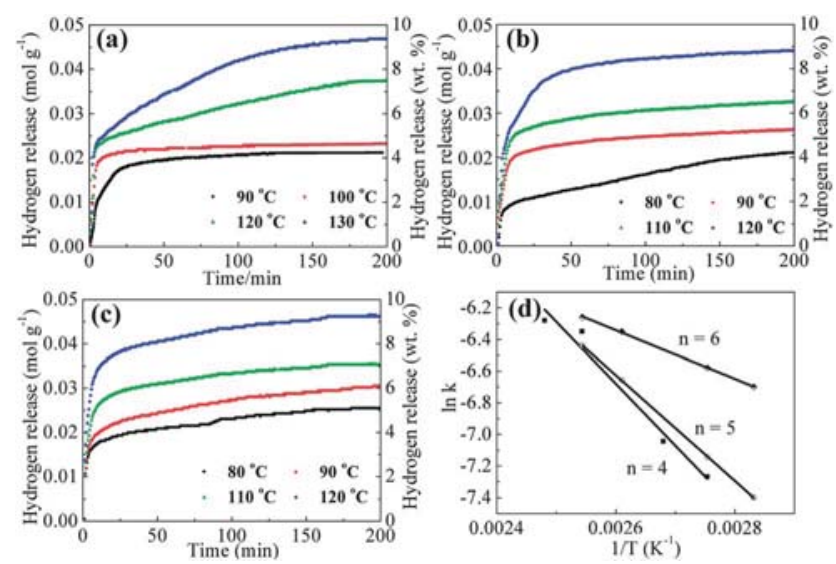

Fig. 6 Isothermal volumetric measurements of hydrogen release from $\mathrm{Li}_{3} \mathrm{AlH}_{6}$ $n A B$ composites when $n=4(a), 5(b)$, and 6 (c) at different temperatures, and (d) Arrhenius plots of the temperature-dependent rate data. $\mathrm{mol}^{-1}$, and $12.8 \mathrm{~kJ} \mathrm{~mol}^{-1}$ for $\mathrm{Li}_{3} \mathrm{AlH}_{6}-n \mathrm{AB}$ composites with $n=$ 4,5 , and 6 , respectively, indicating more favourable hydrogen release properties with increasing $\mathrm{AB}$ content in the raw materials.

\subsection{Decomposition mechanism}

Because the hydrogen release for this system is mainly due to the combination of hydridic hydrogen with protonic hydrogen, i.e., $\mathrm{H}^{\delta+}$ linked to the $\mathrm{N}$ atom with $\mathrm{H}^{\delta-}$ linked to the $\mathrm{B}$ or $\mathrm{Al}$ atom, the decomposition of the $\mathrm{Li}_{3} \mathrm{AlH}_{6}-n \mathrm{AB}(n=4,5$, and 6) composites is determined to be exothermic as confirmed by the DSC results (Fig. 7), which are similar to the behaviour of other metallic amidoboranes..$^{\mathbf{1 0 - 2 0}}$ In particular, upon decomposition, $\mathrm{Li}_{3} \mathrm{AlH}_{6}-4 \mathrm{AB}$ exhibits a small exothermic peak at around $57^{\circ} \mathrm{C}$, which is proposed to be the reaction of residual $\mathrm{Li}_{3} \mathrm{AlH}_{6}$ (Fig. 1) with ammonia borane, and then a major hydrogen release peak at around $100{ }^{\circ} \mathrm{C}$, followed by some small peaks in the region of 116-150 ${ }^{\circ} \mathrm{C}$, consistent with the hydrogen release results from the mass spectra. With the aim of unravelling the relatively intricate decomposition mechanism for the $\mathrm{Li}_{3} \mathrm{AlH}_{6}-n \mathrm{AB}(n=4$, 5 , and 6) composites according to the MS results, in situ highresolution X-ray diffraction was performed to survey the phase transformation during decomposition of the thus-synthesized mixed-metal amidoborane during heating. As shown in Fig. 8, no structural change occurred before $80{ }^{\circ} \mathrm{C}$, but upon further heating, all the peaks belonging to the synthesized mixed-metal amidoborane were significantly weakened at $\sim 80{ }^{\circ} \mathrm{C}$ and disappeared at around $100{ }^{\circ} \mathrm{C}$, indicating that the onset of hydrogen desorption from the mixed-metal amidoborane starts from $\sim 80{ }^{\circ} \mathrm{C}$, which is consistent with the MS results. After heating the sample to $200{ }^{\circ} \mathrm{C}$, the mixed-metal amidoborane decomposed to form an amorphous state, which accounts for the formation of $\mathrm{N}-\mathrm{B}$ chain oligomerization concurrent with the release of hydrogen during the decomposition of the metal amidoboranes. ${ }^{9 b}$ Additionally, a recent study by Pruski's group ${ }^{31}$ found that upon heating, the interaction of a physical mixture of $\mathrm{Li}_{3} \mathrm{AlH}_{6}$ and $\mathrm{AB}$ with a molar ratio of $1: 3$ formed $\mathrm{LiNH}_{2} \mathrm{BH}_{3}$

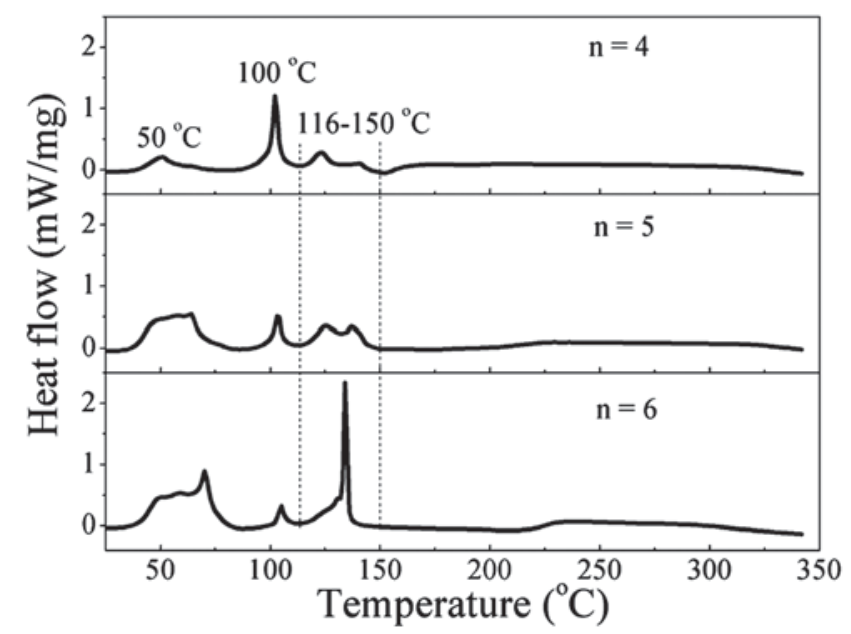

Fig. 7 Differential scanning calorimetry results for $\mathrm{Li}_{3} \mathrm{AlH} \mathrm{H}_{6}-n \mathrm{AB}(n=4,5$, and 6) composites under a heating rate of $2{ }^{\circ} \mathrm{C} \mathrm{min}^{-1}$ in $1 \mathrm{~atm} \mathrm{~N}_{2}$ atmosphere. 


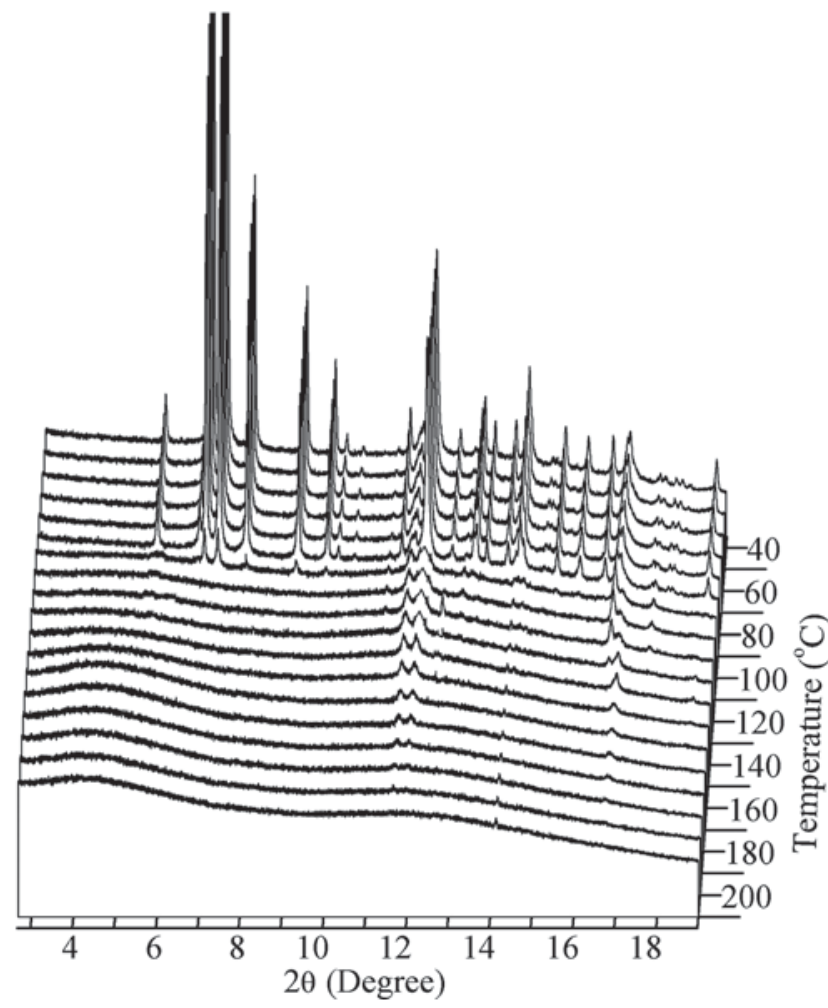

Fig. 8 Selected range of the in situ high-resolution XRD patterns for the postmilled $\mathrm{Li}_{3} \mathrm{AlH}_{6}-4 \mathrm{AB}$ composites at different temperatures.

adducted with $\mathrm{AB}$, which mainly accounts for the accelerated formation of branched polyaminoborane and hydrogen release, with the generation of $\mathrm{AlH}_{3}$ and $\mathrm{LiH}$ as intermediate compounds. However, the post-milled mixtures of $\mathrm{Li}_{3} \mathrm{AlH}_{6}$ and $\mathrm{AB}$ in the present work exhibit a significantly different mechanism from the physical mixture of $\mathrm{Li}_{3} \mathrm{AlH}_{6}$ and $\mathrm{AB}$, as no intermediate compounds, e.g., $\mathrm{LiH}$ and $\mathrm{AlH}_{3}$, were detected in the in situ XRD results for the decomposition of the composite with a molar ratio of $1: 4$, and the XRD results for the dehydrogenated products identify no formation of metallic $\mathrm{Al}$ (Fig. 8 and $\mathrm{S} 4 \dagger$ ). The distinct pathway for hydrogen release may originate from the fact that temperature is an important factor for both the interaction between $\mathrm{Li}_{3} \mathrm{AlH}_{6}$ and $\mathrm{AB}$ and the subsequent decomposition, due to their exothermic nature.

With respect to $\mathrm{Li}_{3} \mathrm{AlH}_{6}-5 \mathrm{AB}$ and $\mathrm{Li}_{3} \mathrm{AlH}_{6}-6 \mathrm{AB}$, exothermic peaks for hydrogen release at temperatures comparable with the MS results for hydrogen evolution were also detected. By contrast, compared with the post-milled $\mathrm{Li}_{3} \mathrm{AlH}_{6}-4 \mathrm{AB}$ sample, due to the presence of residual $\mathrm{AB}$ of the mobile phase in the raw materials for the $\mathrm{Li}_{3} \mathrm{AlH}_{6}-n \mathrm{AB}(n=5$ and 6) composites (Fig. 2), the onset dehydrogenation temperature from the $n=5$ and 6 composites lowered to around $56{ }^{\circ} \mathrm{C}$, and the hydrogen release peaks appeared before the onset hydrogen release temperature of the post-milled $\mathrm{Li}_{3} \mathrm{AlH}_{6}-4 \mathrm{AB}$ sample, as demonstrated by the MS and TGA results. XRD patterns of the $\mathrm{Li}_{3} \mathrm{AlH}_{6}-n \mathrm{AB}$ ( $n=5$ and 6) composites after heating to $90^{\circ} \mathrm{C}$ are presented in Fig. S $5 \dagger$ so that the phase transformation due to the presence of residual $\mathrm{AB}$ originating from hydrogen desorption at temperatures below $90{ }^{\circ} \mathrm{C}$ can be ascertained. Interestingly, the diffraction peaks of the thus-synthesized mixed-metal amidoborane can still be clearly identified in the post-heated samples, although with weakened identity, and the peaks indexed to residual $\mathrm{AB}$ have disappeared, providing direct evidence for the participation of surplus $A B$ of the mobile phase in the hydrogen desorption at temperatures ranging from 56 to $90{ }^{\circ} \mathrm{C}$. In addition, based on the TGA and TPD results, more than 2 equiv. $\mathrm{H}_{2}$, which is the theoretically releasable hydrogen capacity below $200{ }^{\circ} \mathrm{C},{ }^{10 a}$ was detached. Therefore, the hydrogen release below $90{ }^{\circ} \mathrm{C}$ is possibly derived from not only the decomposition of residual $\mathrm{AB}$, but also the cooperative mechanism of $\mathrm{AB}$ with the as-synthesized mixed-metal amidoborane. The interaction of amidoboranes with $\mathrm{AB}$, although in the room temperature phase, is also evidenced by the decomposition of the $\mathrm{LiNH}_{2} \mathrm{BH}_{3} \cdot \mathrm{NH}_{3} \mathrm{BH}_{3}$ system, leading to significantly improved hydrogen release properties due to the combination of $\mathrm{N}-\mathrm{H}$ bonds with $\mathrm{B}-\mathrm{H}$ bonds between the $\mathrm{LiNH}_{2} \mathrm{BH}_{3}$ moiety and the $\mathrm{BH}_{3} \mathrm{NH}_{3}$ moiety, which forms polyaminoborane-like products of an amorphous nature. ${ }^{30}$ The synergistic effects of the interaction of $\mathrm{AB}$ with $\mathrm{LiNH}_{2} \mathrm{BH}_{3}$ is free of any induction period, which is attributed to the disruption of dihydrogen bonds and the slow formation of $\left[\mathrm{NH}_{3} \mathrm{BH}_{2} \mathrm{NH}_{3}\right]^{+}\left[\mathrm{BH}_{4}\right]^{-}$(DADB), which is surmised to be a key reactive species for $\mathrm{H}_{2}$ liberation from $\mathrm{AB} \cdot{ }^{32}$ It is believed that the reaction of the as-synthesized mixed-metal amidoborane with the mobile phase of $A B$ resembles the interaction of $\mathrm{LiNH}_{2} \mathrm{BH}_{3}$ with $\mathrm{AB}$, resulting in improved hydrogen release properties with the formation of amorphous products and the preservation of residual mixedmetal amidoborane, as indicated in the XRD patterns (Fig. S5 $\dagger$ ). Furthermore, due to the decrease and/or weakening of dihydrogen bonds in the mobile $\mathrm{AB}$ phase, ${ }^{27}$ which results in higher reactivity relative to the room temperature phase of $\mathrm{AB}$, the energy barrier for the combination of $\mathrm{N}-\mathrm{H}$ bonds with $\mathrm{B}-\mathrm{H}$ bonds between metallic amidoborane and $\mathrm{AB}$ in the mobile phase is reduced. It, therefore, gives rise to lower onset and peak temperature of hydrogen release for the post-milled $\mathrm{Li}_{3} \mathrm{AlH}_{6}$ $n \mathrm{AB} \quad(n=5$ and 6) composites compared with $\mathrm{LiNH}_{2} \mathrm{BH}_{3} \cdot \mathrm{NH}_{3} \mathrm{BH}_{3},{ }^{30}$ in which the reaction of $\mathrm{LiNH}_{2} \mathrm{BH}_{3}$ with the room temperature phase of $\mathrm{AB}$ leads to the release of hydrogen. In addition, it should be noted that, as indicated from MS and DSC results, the participation of the $\mathrm{AB}$ in the mobile phase in the decomposition of the thus-synthesized mixed-metal amidoborane results in a more intricate dehydrogenation pathway for the post-milled $\mathrm{Li}_{3} \mathrm{AlH}_{6}-n \mathrm{AB}(n=5$ and 6$)$ composites compared with the $\mathrm{Li}_{3} \mathrm{AlH}_{6}-4 \mathrm{AB}$ sample. Obviously, similar to the decomposition mechanism of other metallic amidoboranes, the dihydrogen bonding network and the metal ion assisted hydride transfer are of significant importance for the substantially improved hydrogen release properties compared with ammonia borane. ${ }^{9 a}$

Due to the limited characterization of the materials in the amorphous state that is possible by other techniques, further exploration of the post-heated samples was provided via NMR and FTIR spectra to monitor the chemical environments of $\mathrm{B}$ and $\mathrm{N}$, as shown in Fig. 9. The formation of $\mathrm{sp}^{2}$-hybridized boron and $\mathrm{BN}_{3} \mathrm{H}$, ranging from -10 to $30 \mathrm{ppm}$ and centered at 

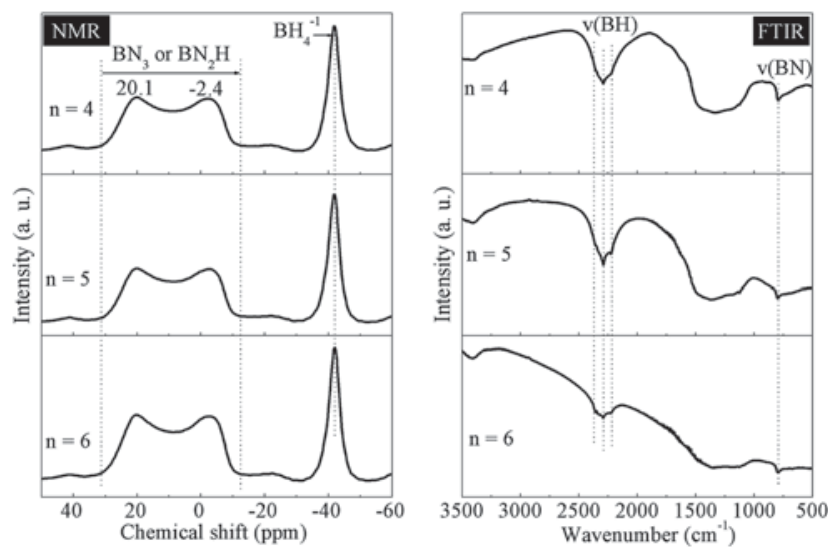

Fig. 9 Solid-state ${ }^{11} \mathrm{~B}$ NMR and FTIR spectra of $\mathrm{Li}_{3} \mathrm{AlH} \mathrm{H}_{6}-n \mathrm{AB}(n=4,5$, and 6) composites upon heating to $350{ }^{\circ} \mathrm{C}$ with a heating rate of $2{ }^{\circ} \mathrm{C} \mathrm{min}^{-1}$.

20.1 and $-2.4 \mathrm{ppm}$, was observed in the ${ }^{11} \mathrm{~B}$ NMR results, in tandem with the fact that most $\mathrm{N}-\mathrm{H}$ stretches disappeared from the FTIR spectra in the post-heated samples, which are reminiscent of the dehydrogenated products of other amidoboranes, ${ }^{10-20}$ further demonstrating that the combination of hydridic $\mathrm{H}^{\delta+}$ and protonic $\mathrm{H}^{\delta-}$ in general accounts for the hydrogen desorption from $\mathrm{Li}_{3} \mathrm{AlH}_{6}-n \mathrm{AB}(n=4,5$, and 6) composites. Interestingly, the presence of an unsaturated boron structure offers significant potential for the regeneration of hydrogen-depleted composites using hydrazine as the reductant in liquid ammonia. ${ }^{2 a}$ In addition to that, a principal signal at $-41 \mathrm{ppm}$, corresponding to the $\mathrm{BH}_{4}{ }^{-}$moiety in the NMR spectra, and B-H stretches in the FTIR spectra are present in the dehydrogenated samples, while no peaks indexed to metal borohydrides are present in the XRD results, indicating the amorphous state of the thus-formed borohydrides. Similar phenomena were observed in the products from the decomposition of lithium amidoborane. ${ }^{10 a}$

\subsection{Regeneration}

The practical application of $\mathrm{Li}_{3} \mathrm{AlH}_{6}-n \mathrm{AB}$ composites lies not only in the hydrogen desorption performance, but also in the hydrogenation conditions of the spent fuel. Efforts to restore the spent fuels were impractical via direct solid-gas reaction, however, due to the exothermicity of the hydrogen release reaction. On the other hand, inspired by recent advances in efficient regeneration of $\mathrm{AB}$ from the highly unsaturated $\mathrm{sp}^{2}$ hybridized boron structure in polyborazylene, which is the predominant environment for boron after dehydrogenation to $350{ }^{\circ} \mathrm{C}$ for $\mathrm{Li}_{3} \mathrm{AlH}_{6}-n \mathrm{AB}$ composites, as shown in Fig. 9, chemical hydrogenation, by treating the decomposed products with hydrazine as the reductant in liquid ammonia, was attempted. To prove the feasibility of this method, firstly, solid-state ${ }^{11} \mathrm{~B}$ NMR spectra were employed to detect the environmental changes experienced by boron in the regenerated products. From the NMR results (Fig. 10), it can be seen that, after regeneration of the dehydrogenated $\mathrm{Li}_{3} \mathrm{AlH}_{6}-n \mathrm{AB}$ composites, a broad peak belonging to $\mathrm{NBH}_{3}$, which was also present in the original samples (Fig. 2), appears. Nevertheless, the presence of

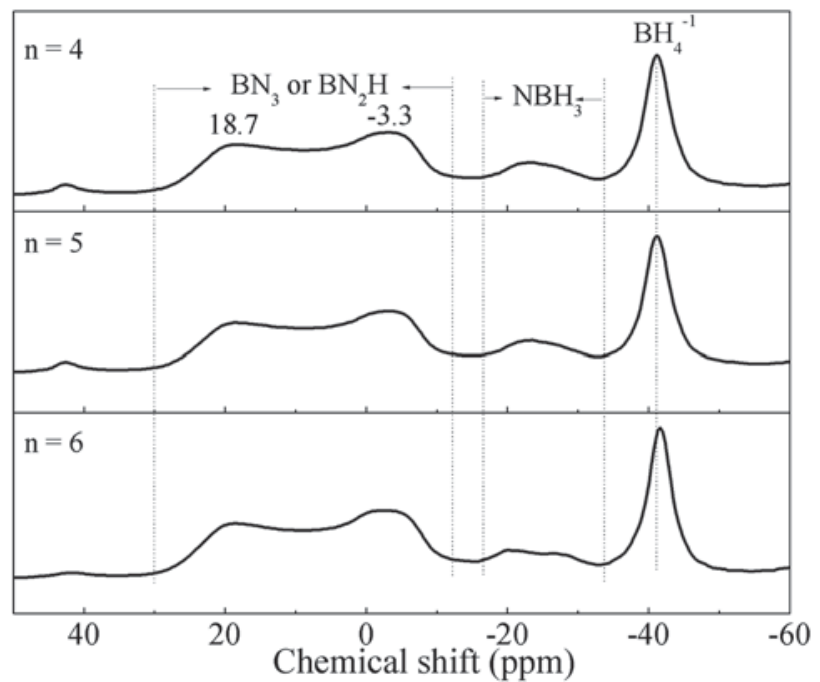

Fig. 10 Solid-state ${ }^{11} \mathrm{~B}$ NMR spectra of $\mathrm{Li}_{3} \mathrm{AlH} \mathrm{H}_{6}-n \mathrm{AB}(n=4,5$, and 6) composites after regeneration from the spent fuels.

unreacted $\mathrm{sp}^{2}$-hybridized boron and the $\mathrm{BN}_{3} \mathrm{H}$ analogue confirms the partial transformation of the unsaturated boron structure to the $\mathrm{NBH}_{3}$ analogue species under the reducing action of hydrazine in liquid ammonia. By contrast with the dehydrogenated products, the intensity ratio between the relative downfield region (centered at $20.1 \mathrm{ppm}$ in the dehydrogenated products and $18.7 \mathrm{ppm}$ in the regenerated products) and the relative upfield region (centered at $-2.4 \mathrm{ppm}$ in the dehydrogenated products and $-3.3 \mathrm{ppm}$ in the regenerated products) was reduced for the regenerated sample, suggesting that the more unsaturated boron structure there is, the more readily it is hydrogenated. This is mainly attributed to the fact that the position of the peak in the downfield region more closely resembles that of the polyborazylene from the decomposition of $\mathrm{AB}$ at $\sim 26 \mathrm{ppm} .{ }^{33}$ Moreover, in comparison with the resonance of the freshly ball-milled counterparts, the regions of the $\mathrm{NBH}_{3}$ resonance for the regenerated composites are substantially broader, indicating that more complicated environments for boron may exist in the regenerated samples. Furthermore, FTIR (Fig. 11) was employed to monitor the bonding changes in the regenerated products. Strong peaks pertinent to the characteristic resonance of $\mathrm{B}-\mathrm{H}$ bonds, corresponding to the distinct peaks of $\mathrm{BH}_{4}$ and $\mathrm{BH}_{3}$ fragments in the NMR spectra, were obtained. However, only weak peaks for $\mathrm{N}-\mathrm{H}$ bonds were observed at the identical positions, suggesting that there are similar chemical environments for $\mathrm{N}-\mathrm{H}$ bonds after regeneration. Based on the mechanism for hydrogenation from polyborazylene to ammonia borane, the $\mathrm{BH}_{3}$ moiety is first formed by combination with residual $\mathrm{N}_{2} \mathrm{H}_{4}$, and then replaced by $\mathrm{NH}_{3}$, leading to the formation of $\mathrm{AB}^{2 a}$ In contrast to $\mathrm{AB}$, in which the $\mathrm{BH}_{3}$ from the $\mathrm{BN}_{3}$ or $\mathrm{BN}_{3} \mathrm{H}$ groups reduced by hydrazine during the process of reduction of decomposed $\mathrm{Li}_{3} \mathrm{AlH}_{6}-n \mathrm{AB}$ composite, substitution is more difficult, probably due to the presence of metal cations, which may interact with the resultant polymeric $\mathrm{BN}_{3}$ or $\mathrm{BN}_{3} \mathrm{H}$ from dehydrogenation leading to strengthened $\mathrm{B}-\mathrm{N}$ bonds compared with pure 


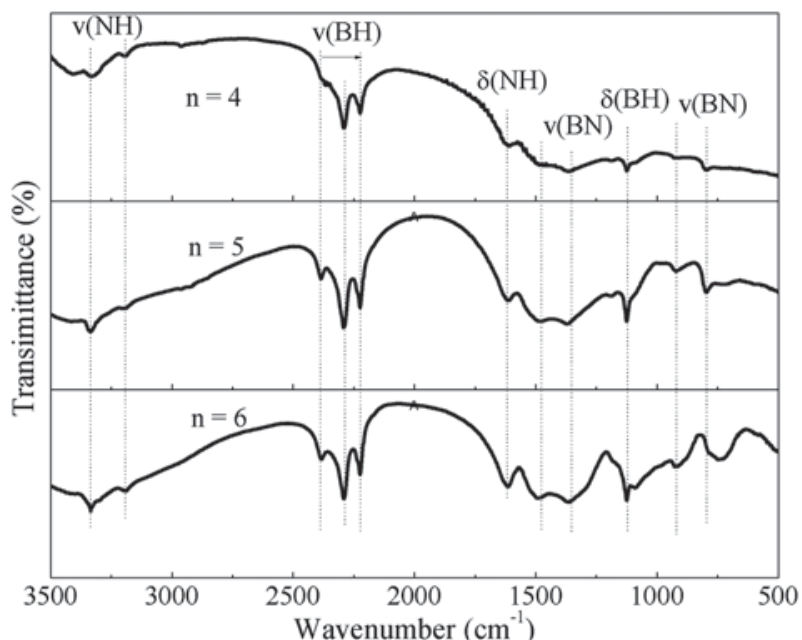

Fig. 11 FTIR spectra of $\mathrm{Li}_{3} \mathrm{AlH}{ }_{6}-n \mathrm{AB}(n=4,5$, and 6$)$ composites after regeneration from the spent fuels.

polyborazylene formed from the decomposition of ammonia borane. Therefore, the chemical regeneration of the spent fuel from $\mathrm{Li}_{3} \mathrm{AlH}_{6}-n \mathrm{AB}$ composites upon treatment with hydrazine in liquid ammonia gives rise to partial regeneration in comparison with the $95 \%$ yield for the regeneration of $\mathrm{AB}$ from polyborazylene. Additionally, with increasing $\mathrm{AB}$ content in the raw materials, the intensity of the $\mathrm{N}-\mathrm{H}$ bonds in the related products after regeneration increases, suggesting that more $\mathrm{N}-$ $\mathrm{H}$ bonds are present. It is worth noting that, due to the presence of excess $\mathrm{AB}$ in the $\mathrm{Li}_{3} \mathrm{AlH}_{6}-n \mathrm{AB}(n=5$ and 6$)$ composites, the possible regeneration of the $\mathrm{NH}_{3}$ group in $\mathrm{AB}$ may partially account for the presence of some $\mathrm{N}-\mathrm{H}$ bonds in the related products after regeneration.

Further evidence for the successful regeneration of the dehydrogenated $\mathrm{Li}_{3} \mathrm{AlH}_{6}-n \mathrm{AB}$ composites was obtained by employing MS spectra and volumetric measurements. Impressively, hydrogen is the exclusive product detectable by MS from the regeneration products (Fig. 12), even for the regenerated $\mathrm{Li}_{3} \mathrm{AlH}_{6}-6 \mathrm{AB}$ sample, in which the decomposition of the freshly milled composite shows ammonia as a by-product coupled with the main release of hydrogen, as displayed in Fig. 4. Moreover, in contrast to the as-milled samples, all the regenerated composites start to release hydrogen at approximately $70{ }^{\circ} \mathrm{C}$, with the first peak centered at around the same temperature of $128{ }^{\circ} \mathrm{C}$, which is a little higher than the freshly ball-milled composites. This resemblance is probably due to their comparable $\mathrm{H}$ environments, connected to $\mathrm{B}$ and $\mathrm{N}$, as indicated by the FTIR and NMR spectra for the samples after regeneration. According to the TPD results (Fig. 13), all the regenerated $\mathrm{Li}_{3} \mathrm{AlH}_{6}-n \mathrm{AB}(n=4,5$, and 6$)$ composites show a dehydrogenation capacity of around $3.5 \mathrm{wt} \%$, corresponding to an approximate $35 \%, 30 \%$, and $26 \%$ regeneration yield for the post-milled $\mathrm{Li}_{3} \mathrm{AlH}_{6}-n \mathrm{AB}$ composites with $n=4,5$, and 6 , respectively. Due to the partial regeneration of unsaturated $\mathrm{B}-\mathrm{N}$ bonds and formation of stable $\mathrm{BH}_{4}$ groups during decomposition, the second dehydrogenation capacity of the regenerated $\mathrm{Li}_{3} \mathrm{AlH}_{6}-6 \mathrm{AB}$ was decreased to less than $1.5 \mathrm{wt} \%$ (Fig. S6†), only accounting for around $11 \%$ regeneration yield.

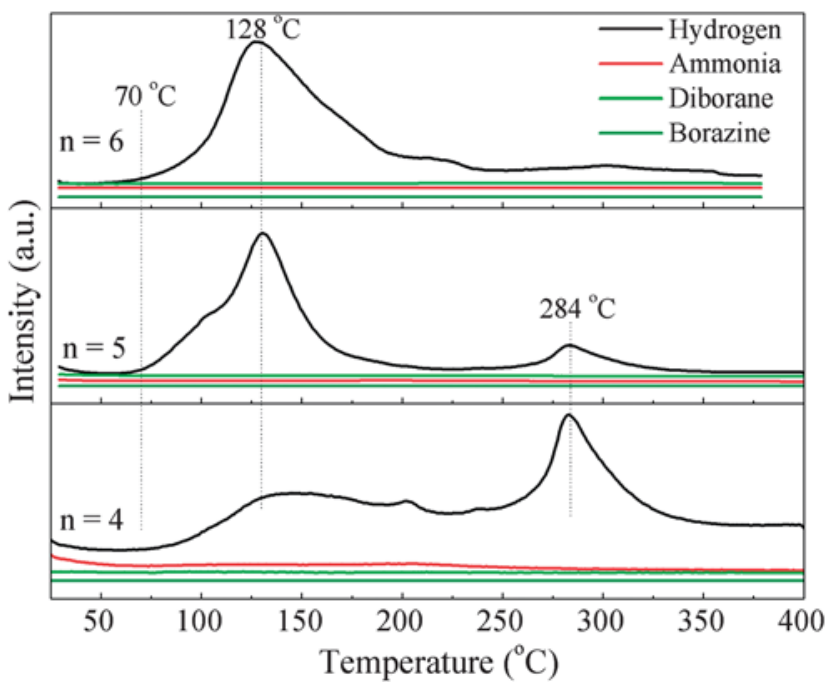

Fig. 12 MS spectra of the $\mathrm{Li}_{3} \mathrm{AlH}_{6}-n \mathrm{AB}(n=4,5$, and 6) composites after regeneration from the spent fuels.

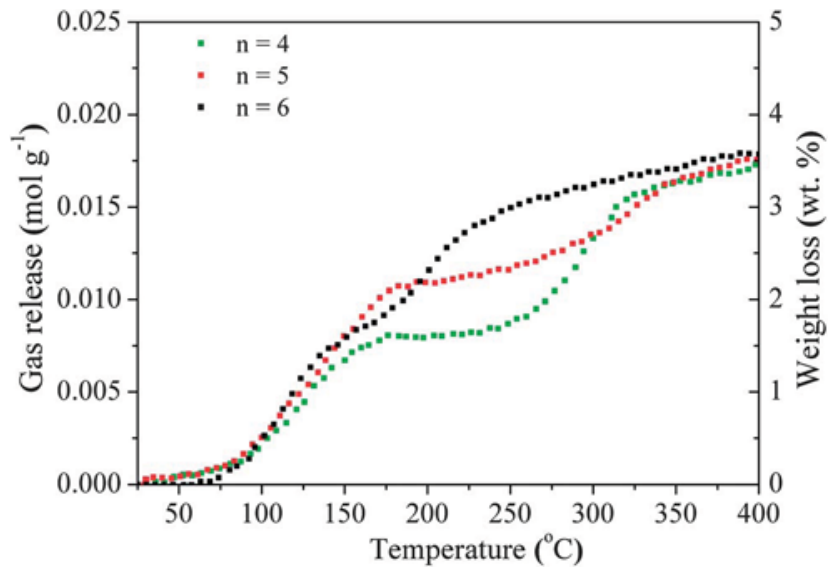

Fig. 13 TPD results for the decomposition of $\mathrm{Li}_{3} \mathrm{AlH}_{6}-n \mathrm{AB}(n=4,5$, and 6) composites after regeneration from the spent fuels.

From Fig. 12 and 13, it can be seen that the samples after hydrogenation exhibit various traits, with distinct two-step dehydrogenation for the regenerated $\mathrm{Li}_{3} \mathrm{AlH}_{6}-n \mathrm{AB}(n=4$, and 5) composites, while the regenerated $\mathrm{Li}_{3} \mathrm{AlH}_{6}-6 \mathrm{AB}$ shows superior dehydrogenation kinetics at relatively lower temperatures. According to the IR spectra, the $\mathrm{N}-\mathrm{H}$ bond content in the regenerated products increases with increasing content of ammonia borane, consequently leading to an excess of B-H bonds in the regenerated samples from $\mathrm{Li}_{3} \mathrm{AlH}_{6}-n \mathrm{AB}(n=4$ and 5) composites in comparison with $\mathrm{Li}_{3} \mathrm{AlH}_{6}-6 \mathrm{AB}$, in which the decomposition accounts for the $2^{\text {nd }}$ step hydrogen desorption upon further heating. This can be further confirmed by the disappearance of $\mathrm{N}-\mathrm{H}$ bonds in the rehydrogenated samples from the $\mathrm{Li}_{3} \mathrm{AlH}_{6}-4 \mathrm{AB}$ composite after heating to $250^{\circ} \mathrm{C}$ and the presence of weakened $\mathrm{B}-\mathrm{H}$ bonds due to their consumption in the reaction with $\mathrm{N}-\mathrm{H}$ bonds, as shown in Fig. S7. $†$ Indeed, even after dehydrogenation to $400{ }^{\circ} \mathrm{C}, \mathrm{B}-\mathrm{H}$ bonds are still present, 
which is attributable to the presence of relatively stable $\mathrm{BH}_{4}{ }^{-}$ groups like those in alkali metal borohydrides. ${ }^{34}$

\section{Conclusion}

By incorporation of alkali metal, alkali metal (Li) and trivalent metal (Al) based metallic amidoborane was successfully prepared. The significantly enhanced hydrogen release properties at low temperature, together with the effective suppression of volatile by-products, make it a promising hydrogen storage candidate. It has been shown through volumetric measurements that this novel compound is able to release $9 \mathrm{wt} \% \mathrm{H}_{2}$ at the temperature of $130{ }^{\circ} \mathrm{C}$ within $200 \mathrm{~min}$. Furthermore, promotion of hydrogen release from $\mathrm{AB}$ through its interaction with the thus-prepared mixed-metal amidoborane was found, including effective suppression of boric by-products and improved hydrogen release kinetics compared with the components, i.e., over $9 \mathrm{wt} \% \mathrm{H}_{2}$ released at $120{ }^{\circ} \mathrm{C}$ within $200 \mathrm{~min}$. The products after regeneration are able to release around $3.5 \mathrm{wt} \% \mathrm{H}_{2}$ corresponding to a $35 \%$ regeneration yield for the post-milled $\mathrm{Li}_{3} \mathrm{AlH}_{6}-4 \mathrm{AB}$ composite. These advances may open up the possibility of exploring amidoboranes as a series of practical hydrogen storage materials. In order to commercialize this route using amidoboranes as hydrogen carriers, however, more issues, especially for the enhancement of recyclable hydrogen capacity, still need to be addressed in the future.

\section{Acknowledgements}

This work was partially supported by the Ministry of Science and Technology of China (2010CB631302), the National Natural Science Foundation of China (Grant no. 51071047, 21271046), the PhD Programs Foundation of the Ministry of Education of China (20110071110009) and the Science and Technology Commission of Shanghai Municipality (11JC1400700, 115207011100). Z. Guo acknowledges financial support from the Australian Research Council (ARC) discovery project (grant number DP1094261). Part of this research was undertaken on the Powder Diffraction Beamline at the Australian Synchrotron, Victoria, Australia. The authors also would like to thank Dr Tania Silver for critical reading of the manuscript.

\section{Notes and references}

1 (a) T. K. A. Hoang and D. M. Antonelli, Adv. Mater., 2009, 21, 1787-1800; (b) L. Schlapbach and A. Zuttel, Nature, 2001, 414, 353-358; (c) S. Orimo, Y. Nakamori, J. R. Eliseo, A. Züttel and C. M. Jensen, Chem. Rev., 2007, 107, 4111-4132. 2 (a) A. D. Sutton, A. K. Burrell, D. A. Dixon, E. B. Garner III, J. C. Gordon, T. Nakagawa, K. C. Ott, J. P. Robinson and M. Vasiliu, Science, 2011, 331, 1426-1429; (b) B. L. Davis, D. A. Dixon, E. B. Garner, J. C. Gordon, M. H. Matus, B. Scott and F. H. Stephens, Angew. Chem., Int. Ed., 2009, 48, 6812-6816; (c) A. D. Sutton, B. L. Davis, K. X. Bhattacharyya, B. D. Ellis, J. C. Gordon and P. P. Power, Chem. Commun., 2010, 46, 148-149.
3 (a) A. Staubitz, A. P. M. Robertson and I. Manners, Chem. Rev., 2010, 110, 4079-4124; (b) W. Grochala and P. P. Edwards, Chem. Rev., 2004, 104, 1283-1315.

4 (a) L. Li, X. Yao, C. Sun, A. Du, L. Cheng, Z. Zhu, C. Yu, J. Zou, S. C. Smith, P. Wang, H.-M. Cheng, R. L. Frost and G. Q. Lu, Adv. Funct. Mater., 2009, 19, 265-271; (b) A. Gutowska, L. Li, Y. Shin, C. M. Wang, X. S. Li, J. C. Linehan, R. S. Smith, B. D. Kay, B. Schmid, W. Shaw, M. Gutowski and T. Autrey, Angew. Chem., Int. Ed., 2005, 44, 3578-3582; (c) S. Sepehri, B. B. García and G. Cao, Eur. J. Inorg. Chem., 2009, 2009, 599-603; (d) S. F. Li, Y. H. Guo, W. W. Sun, D. L. Sun and X. B. Yu, J. Phys. Chem. C, 2010, 114, 21885-21890; (e) T. Zhang, X. Yang, S. Yang, D. Li, F. Cheng, Z. Tao and J. Chen, Phys. Chem. Chem. Phys., 2011, 13, 18592-18599; (f) T. K. Nielsen, F. Besenbacher and T. R. Jensen, Nanoscale, 2011, 3, 2086-2098.

5 (a) T. He, Z. T. Xiong, G. T. Wu, H. L. Chu, C. Z. Wu, T. Zhang and P. Chen, Chem. Mater., 2009, 21, 2315-2318; (b) B. L. Conley, D. Guess and T. J. Williams, J. Am. Chem. Soc., 2011, 133, 14212-14215; (c) S. B. Kalidindi, J. Joseph and B. R. Jagirdar, Energy Environ. Sci., 2009, 2, 12741276.

6 (a) M. E. Bluhm, M. G. Bradley, R. Butterick, U. Kusari and L. G. Sneddon, J. Am. Chem. Soc., 2006, 128, 7748-7749; (b) D. W. Himmelberger, C. W. Yoon, M. E. Bluhm, P. J. Carroll and L. G. Sneddon, J. Am. Chem. Soc., 2009, 131, 14101-14110.

7 (a) X. B. Zhang, S. Han, J. M. Yan, M. Chandra, H. Shioyama, K. Yasuda, N. Kuriyama, T. Kobayashi and Q. Xu, J. Power Sources, 2007, 168, 167-171; (b) D. Sun, V. Mazumder, O. n. Metin and S. Sun, ACS Nano, 2011, 5, 64586464.

8 P. Wang, Dalton Trans., 2012, 41, 4296-4302.

9 (a) A. T. Luedtke and T. Autrey, Inorg. Chem., 2010, 49, 39053910; (b) D. Y. Kim, H. M. Lee, J. Seo, S. K. Shin and K. S. Kim, Phys. Chem. Chem. Phys., 2010, 12, 5446-5453.

10 (a) Z. T. Xiong, C. K. Yong, G. T. Wu, P. Chen, W. Shaw, A. Karkamkar, T. Autrey, M. O. Jones, S. R. Johnson, P. P. Edwards and W. I. F. David, Nat. Mater., 2008, 7, 138141; (b) C. Wu, G. Wu, Z. Xiong, W. I. F. David, K. R. Ryan, M. O. Jones, P. P. Edwards, H. Chu and P. Chen, Inorg. Chem., 2010, 49, 4319-4323; (c) H. Wu, W. Zhou and T. Yildirim, J. Am. Chem. Soc., 2008, 130, 14834-14839; (d) X. D. Kang, Z. Z. Fang, L. Y. Kong, H. M. Cheng, X. D. Yao, G. Q. Lu and P. Wang, Adv. Mater., 2008, 20, 27562759.

11 (a) Z. T. Xiong, G. T. Wu, Y. S. Chua, J. J. Hu, T. He, W. L. Xu and P. Chen, Energy Environ. Sci., 2008, 1, 360-363; (b) K. Shimoda, Y. Zhang, T. Ichikawa, H. Miyaoka and Y. Kojima, J. Mater. Chem., 2011, 21, 2609-2615.

12 H. V. K. Diyabalanage, T. Nakagawa, R. P. Shrestha, T. A. Semelsberger, B. L. Davis, B. L. Scott, A. K. Burrell, W. I. F. David, K. R. Ryan, M. O. Jones and P. P. Edwards, J. Am. Chem. Soc., 2010, 132, 11836-11837.

13 H. V. K. Diyabalanage, R. P. Shrestha, T. A. Semelsberger, B. L. Scott, M. E. Bowden, B. L. Davis and A. K. Burrell, Angew. Chem., Int. Ed., 2007, 46, 8995-8997. 
14 J. Spielmann, G. Jansen, H. Bandmann and S. Harder, Angew. Chem., Int. Ed., 2008, 47, 6290-6295.

15 Q. Zhang, C. Tang, C. Fang, F. Fang, D. Sun, L. Ouyang and M. Zhu, J. Phys. Chem. C, 2010, 114, 1709-1714.

16 R. V. Genova, K. J. Fijalkowski, A. Budzianowski and W. Grochala, J. Alloys Compd., 2010, 499, 144-148.

17 K. J. Fijalkowski and W. Grochala, J. Mater. Chem., 2009, 19, 2043-2050.

18 K. J. Fijalkowski, R. V. Genova, Y. Filinchuk, A. Budzianowski, M. Derzsi, T. Jaron, P. J. Leszczynski and W. Grochala, Dalton Trans., 2011, 40, 4407-4413.

19 X. Kang, J. Luo, Q. Zhang and P. Wang, Dalton Trans., 2011, 40, 3799-3801.

20 H. Wu, W. Zhou, F. E. Pinkerton, M. S. Meyer, Q. Yao, S. Gadipelli, T. J. Udovic, T. Yildirim and J. J. Rush, Chem. Commun., 2011, 47, 4102-4104.

21 Y. S. Chua, W. Li, G. Wu, Z. Xiong and P. Chen, Chem. Mater., 2012, 24, 3574-3581.

22 X. Kang, L. Ma, Z. Fang, L. Gao, J. Luo, S. Wang and P. Wang, Phys. Chem. Chem. Phys., 2009, 11, 2507-2513.

23 (a) D. Ravnsbaek, Y. Filinchuk, Y. Cerenius, H. J. Jakobsen, F. Besenbacher, J. Skibsted and T. R. Jensen, Angew. Chem., Int. Ed., 2009, 48, 6659-6663; (b) R. Černý, K. Chul Kim, N. Penin, V. D'Anna, H. Hagemann and D. S. Sholl, J. Phys. Chem. C, 2010, 114, 19127-19133.

24 S. Liu, Y. Zhang, L. Sun, J. Zhang, J. Zhao, F. Xu and F. Huang, Int. J. Hydrogen Energy, 2010, 35, 45544561.

25 A. C. Stowe, W. J. Shaw, J. C. Linehan, B. Schmid and T. Autrey, Phys. Chem. Chem. Phys., 2007, 9, 1831-1836.
26 Z. T. Xiong, Y. S. Chua, G. T. Wu, W. L. Xu, P. Chen, W. Shaw, A. Karkamkar, J. Linehan, T. Smurthwaite and T. Autrey, Chem. Commun., 2008, 5595-5597.

27 W. J. Shaw, M. Bowden, A. Karkamkar, C. J. Howard, D. J. Heldebrant, N. J. Hess, J. C. Linehan and T. Autrey, Energy Environ. Sci., 2010, 3, 796-804.

28 J. Yang, X. Wang, J. Mao, L. Chen, H. Pan, S. Li, H. Ge and C. Chen, J. Alloys Compd., 2010, 494, 58-61.

29 H. Zhang, Y. S. Loo, H. Geerlings, J. Lin and W. S. Chin, Int. J. Hydrogen Energy, 2010, 35, 176-180.

30 C. Wu, G. Wu, Z. Xiong, X. Han, H. Chu, T. He and P. Chen, Chem. Mater., 2009, 22, 3-5.

31 T. Kobayashi, I. Z. Hlova, N. K. Singh, V. K. Pecharsky and M. Pruski, Inorg. Chem., 2012, 51, 4108-4115.

32 W. J. Shaw, M. Bowden, A. Karkamkar, C. J. Howard, D. J. Heldebrant, N. J. Hess, J. C. Linehan and T. Autrey, Energy Environ. Sci., 2010, 3, 796-804.

33 (a) P. J. Fazen, J. S. Beck, A. T. Lynch, E. E. Remsen and L. G. Sneddon, Chem. Mater., 1990, 2, 96-97; (b) P. J. Fazen, E. E. Remsen, J. S. Beck, P. J. Carroll, A. R. McGhie and L. G. Sneddon, Chem. Mater., 1995, 7, 1942-1956.

34 (a) P. Mauron, F. Buchter, O. Friedrichs, A. Remhof, M. Bielmann, C. N. Zwicky and A. Zuttel, J. Phys. Chem. B, 2007, 112, 906-910; (b) P. Martelli, R. Caputo, A. Remhof, P. Mauron, A. Borgschulte and A. Züttel, J. Phys. Chem. C, 2010, 114, 7173-7177; (c) A. Züttel, S. Rentsch, P. Fischer, P. Wenger, P. Sudan, P. Mauron and C. Emmenegger, $J$. Alloys Compd., 2003, 356-357, 515-520; (d) A. Züttel, P. Wenger, S. Rentsch, P. Sudan, P. Mauron and C. Emmenegger, J. Power Sources, 2003, 118, 1-7. 